\author{
Stanisław ŁOBEJKO, PhD, Professor of Warsaw School of Economics \\ Collegium of Business Administration, Warsaw School of Economics \\ e-mail: slobej@sgh.waw.pl \\ ORCID: 0000-0003-2337-186X
}

DOI: $10.15290 /$ oes.2020.02.100.03

\title{
DIGITAL TRANSFORMATION AND INNOVATIVENESS OF ENTERPRISES ${ }^{1}$
}

\begin{abstract}
Summary
Purpose - The main objective of the article is an attempt to assess whether and how the digital transformation will affect the innovativeness of companies

Research method - In the article, two basic research questions were formulated: 1. Does digital transformation affect the company's innovation and if so, how? and 2. Can digital transformation change the structure and way of running a business in such a way that innovation can be more closely related to the entrepreneurial attitude of employees? The search for answers to these research questions was based on the analysis of published research results, collected information on the processes of digitization and examples of companies implementing digital technologies and developing digital business models. The analysis of the impact of digital transformation on the innovativeness of enterprises was carried out taking into account two perspectives: macro - digital institutional transformation of the economy and micro - digital transformation of the enterprise.

Results - The thesis that the digital transformation of the company does not guarantee the growth of the company's innovativeness, but its absence will be a strong barrier to the innovation will be formulated and evaluated in the article. The second thesis assumes that thanks to digital transformation enterprises can be more innovative and their employees more entrepreneurial. Conducted analyses allow for a positive verification of the theses formulated in the article and drawing the following conclusion: if companies want to consider innovations, they should undergo a technological transformation that will allow them to take full advantage of the opportunities that digital technologies offer in business.

Originality / value - The article showed that digital technologies and, in particular, digital technology platforms offer the company's employees the possibility of returning to the original Schumpeterian idea of the entrepreneur as an innovator. In the new digital model of the company based on a digital platform, each employee becomes an entrepreneur and at the same time has the opportunity to create innovation in close cooperation with the end user, and thus be an entrepreneur and an innovator.
\end{abstract}

Keywords: digital transformation, innovation, entrepreneurship

JEL Classification: L20, L26, O30

1 Article received on 07 July 2019, accepted on 25 March 2020.

Article received support from the Ministry of Science and Higher Education grants to maintain research potential of the Collegium of Business Administration, Warsaw School of Economics. 


\section{Introduction}

For several decades, we have been observing a rapid development of digital technologies, which significantly changed both the social sphere and the economy. Today, the digital revolution has a substantial impact on all areas of life, changing the existing rules of functioning of markets and enterprises. Enterprises that want to be competitive in the digital economy need to undergo a digital transformation. The digital transformation of enterprises, and especially of business models, means that there is an urgent need to develop and implement new methods and techniques of company management. It also poses a new challenge for business management science. According to Schumpeter, every entrepreneur is an innovator and thanks to entrepreneurs, economic development takes place [Schumpeter, 1912]. His theory gained special significance in the second half of the twentieth century, when the rapid economic development of the world began. Its driving force was scientific and technical progress and the dynamic development of technology. Information and communication technologies, the Internet and wireless communications have had a particularly strong influence. Thanks to modern technologies, the world has become different in many aspects. It involved, in particular, the creation of computer networks enabling faster information exchange and virtualization of enterprises' operations. Further development of information and communication technologies enables the emergence of social networks and, as a result, the world becomes a "global village" in which everyone can communicate with each other in real time, regardless of where they are at a given moment. All this causes the conditions of enterprises' operations to change, therefore they must find their way of development in this new reality.

A rapid development of digital technologies has been observed for many decades. This development has influenced and significantly changed both the social sphere and the economy. Today, the digital revolution has a substantial impact on all areas of life, changing the existing rules of functioning of markets and enterprises. Enterprises that want to be competitive in the digital economy need to undergo a digital transformation. The digital transformation of enterprises, and especially of business models, means that there is an urgent need to develop and implement new methods and techniques of company management. It also poses a new challenge for business management science.

\section{The role of the government}

The phenomenon of digitization is not only about modern, super intelligent technologies but, above all, it is the socio-economic phenomenon affecting the civilizational development of the world. It is expected that the result of the ongoing digitization will be the accelerated development of the digital economy, digital society and digital state, which will be based on artificial intelligence. The digital state has a particularly important role to play. Thanks to digital technologies, it can 
become a leader and organizer of change processes facilitating the development of the digital economy and the digital society. The digital state, thanks to the digitization of administrative and management processes, will be the driving force for the development of new business models and the growth of enterprises' innovativeness.

\section{CHART 1}

\section{The digital state as the foundation for the development of enterprises' innovativeness}

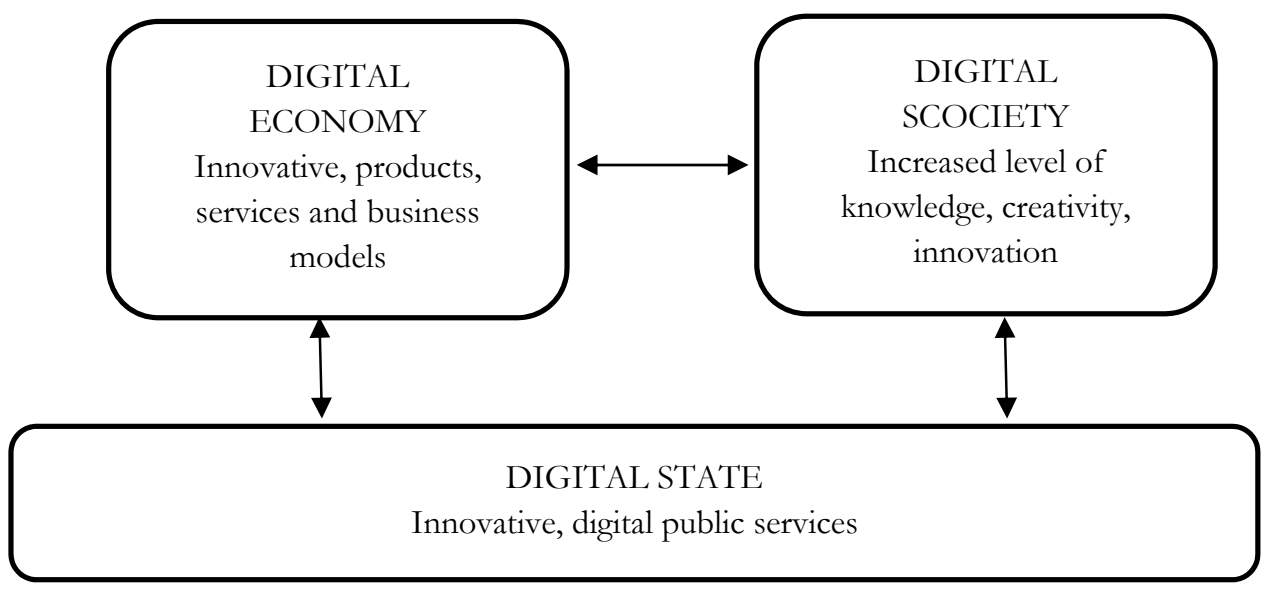

Source: own elaboration.

Providing innovative public services with various channels and means of electronic communication will bring tangible benefits to citizens and entrepreneurs. However, lack of digitization of the state or its slow development results in slowing down the digitization of the economy and society. Therefore, it is necessary to systemically transform the rules of functioning of the public sector, taking into account the perspective of the entire state, not individual units.

\section{The concept of digital transformation}

Digital transformation of each organization is such a transformation of its resources, structures and principles of functioning that enables it to take full advantage of the opportunities offered by modern digital technologies in order to become more and more effective. As a result, public sector organizations should provide services in the form of an integrated, multi-channel approach (traditional and digital), based on personal, postal and network contact (on-line, mobile access, digital TV). An important feature of the digital transformation of the state is that the citizen is treated not only as a client (recipient) using public administration services but, above all, as the owner and participant in the process of creating digital public services. 
At the micro level, digital transformation is very often perceived as the implementation of digital technologies in all areas of the company's business operations. Thinking about digital technology, we assume that it supports discovering new boundaries and using innovations and technologies to push business into new directions. Digital transformation offers new opportunities for an existing service to design and deliver better customer experience thanks to new ways of interacting with clients. There are many different definitions of digital transformation. The basic definition determines it as the novel use of digital technology to solve traditional problems. But digital transformation is also defined as the integration of digital technology into all areas of a business, fundamentally changing the ways of how companies operate and deliver value to customers. In other words, digital transformation includes all changes associated with the application and integration of digital technology into all aspects of human life and society. It enables a move from the physical to the digital. The definition of digital business transformation proposed by Gartner is: "digital business transformation is the process of exploiting digital technologies and supporting capabilities to create a robust new digital business model". It can be stated that digital transformation refers to how a company has transformed or is transforming its core business processes using digital technology to gain competitive advantage and strengthen collaboration and interaction between its partners as well as offer greater value to the customers. "According to IBM research, companies seeking opportunities in an era of constant customer connectivity focus on two complementary activities: reshaping customer value propositions and transforming their operations using digital technologies for greater customer interaction and collaboration."'Berman, 2012, 16-24]. Digital technologies facilitate contact and establishing cooperation with clients at any time when value is created. This close cooperation with the client enables the creation of a new customeroriented business model that accelerates the development of innovation through online communities. Companies conducting digital transformation should, as the main goal, focus their activities on optimizing the value chain around increasing customer engagement. Saul J. Berman in his publication emphasizes that: "Transforming the customer experience is at the heart of digital transformation." [Westerman et al., 2014, p. 29].

Adapting products and services to the digital economy is one of the most important challenges for business managers. The company's digital transformation can ensure its continuity in the market in the future, but it does not guarantee uniqueness or can have a destructive impact on the market or industry. For many managers, digital transformation is associated with a breakthrough in business and is in fact a follow-up to changes caused by digital disturbances [Kletzkine, 2018]. "Companies will continue to develop many great products using a deep understanding of customer needs and well-managed development processes." [Revolutionizing Innovation..., 2016, 474]. Digital technologies make it easier to identify unmet consumer needs and individual expectations. It becomes possible thanks to the use of information technologies to acquire, collect and process large data sets. Thanks to the digital recording of data and information, the use of Big Data analytics and data 
mining is possible and enables the creation of information supporting company management. Detailed information about the consumer's needs allows the company to implement a development strategy based on personalization of products. That is why we are observing a still growing demand for timely and exact information about the needs of the consumer. It should be emphasized that, apart from the known ones, there are also unarticulated customer's needs which are more difficult to recognize. In particular, in the field of high-tech, advanced products, consumers' knowledge about the needs the products meet may be poor. These new needs for customer can be created by a company offering a modern, innovative product, providing a new quality for the market.

\section{Digital transformation and innovation}

The concepts of innovation and transformation are quite often treated as synonyms. In fact, these concepts are equivalent only in some cases. In most cases they differ fundamentally. Transformation is usually a process that lasts for a certain period of time, while innovation may appear as a result of a sudden spark or creativity. The difference between the concepts is particularly evident in the case of digital transformation, which means the process of technology implementation improving business in order to enhance consumer experience. It can include improving operational efficiency, changing the company's culture and image, its structure and a business model.

Schumpeter understood innovations extensively as: (1) the introduction of new products or the improvement of existing ones, (2) the introduction of a new or improved production method, (3) the opening of a new market, (4) the use of a new way of selling or shopping, (5) the use of new raw materials or semi-finished products, (6) the introduction of a new production organization [Schumpeter, 1934, p. 66]. With regard to competition on the market and treating innovation as a competitive advantage factor, innovations can be divided into five categories: (1) a new product, (2) a new method of production, (3) a new market, (4) a new source of supply for materials/pre-manufactured goods, and (5) the emergence of new organizations that create or abolish monopolistic market structures. In digital economy each category can have a destructive impact on the industry, sector or the whole economy. Innovations in a company can play a dual role: supporting innovations already existing on the market and destructive - replacing these innovations. In the contemporary digital economy, the sixth category is becoming increasingly important, namely digital technologies. This category includes all technologies, methods and techniques broadly understood as digital technologies. 
CHART 2

\section{The impact of digital transformation on the company's fields of innovation}

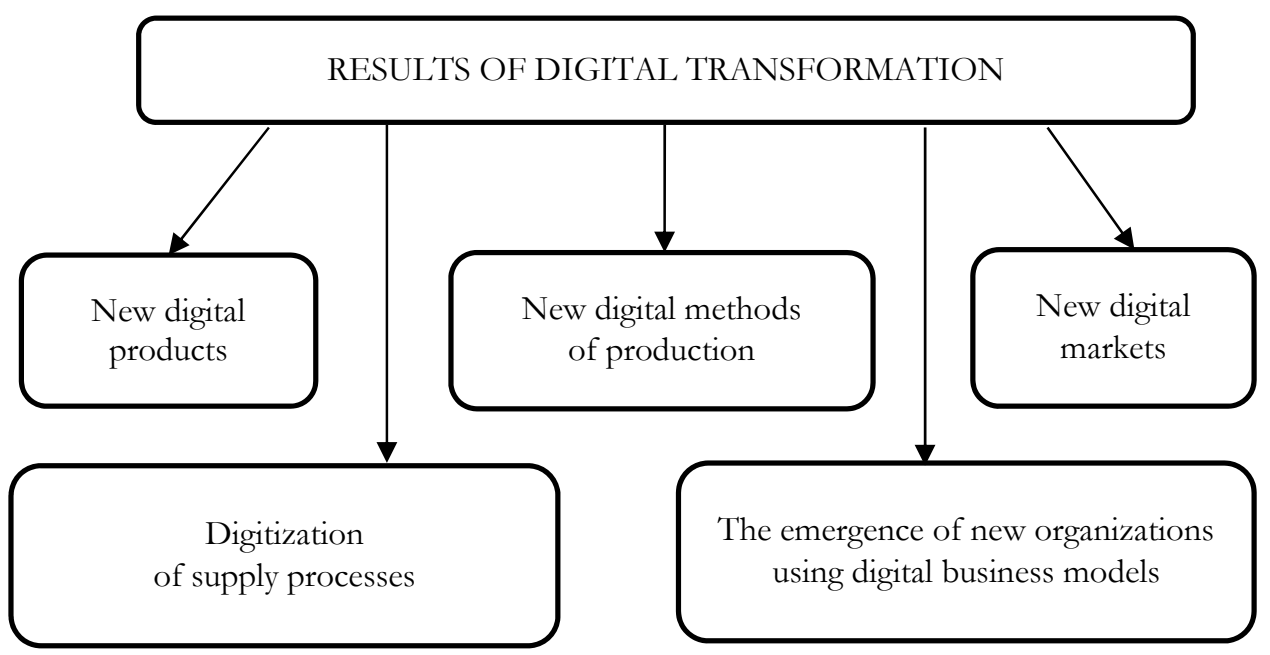

Source: own elaboration

Digital transformation affects the way companies operate and their business models. It enables the introduction of completely new, previously unknown business models based on digital technology platforms, which allows them to gain a competitive advantage. The term digital technology platform is understood as common infrastructure necessary for many applications supporting a product or a group of products [Agarwal, 2018]. Digital platforms, enabling the use of common infrastructure for developing applications, benefit from the multiplier effect that arises thanks to the synergy resulting from the cooperation of many partners. As the experience of many companies has shown so far, breakthrough innovations that break the existing order in the industry or sector and introduce new business rules as well as new business models will become more important for the company success in the market [Christensen, 1997]. It should be emphasized that new business models based on digital platforms will be accompanied by changes in the organizational structures of enterprises - from being hierarchically organized towards flat structures based on teamwork.

Digital platforms can play an important role in the transformation of all industries. According to de Reuver et al. [2018, p. 7], digital platforms can play a disruptive role in shaping the entire industries. Also, Parker points to the emergence of platform thinking and the transformative and disruptive impact of digital platforms on organizations, their business models and the business environment as a whole [Parker et al., 2016]. All this means that conducting research on new theories and 
models which explain and predict the potentially disruptive nature of digital platforms will be necessary [de Reuver et al., 2018, pp. 7-8].

There is no doubt that we live in the world where everything is changing, and that the only thing that is constant is the process of continuous change. For many years, we have been observing changes taking place in business models driven by new technologies, new methods of production, distribution and marketing. These factors do not only modify the already existing business models but also enable the creation of entirely new ones. One of the main driving forces behind the change process are digital technologies that force businesses to change their existing model of operation to a completely new one. Such change is possible thanks to the digital transformation of enterprises enabling a shift from their traditional mode of operation and management to the modern and technology-oriented ways of operation. Delivering a good digital business experience to customers and employees is the main goal of the changes that are taking place. Strong market competition makes it necessary to reduce operational costs and enhance customer experience as a result of digital transformation.

\section{Digital destruction and company innovativeness}

Many contemporary disruptive innovations are based on new, highly advanced technologies and, in particular, on digital technologies. Digital technologies are currently becoming one of the main drivers of economic development and the foundation for the fourth industrial revolution and a new industry known as Industry 4.0. Today, it is hard to imagine the functioning of a modern economy without digital technologies. Their influence on the economy is more and more often destructive but in a positive sense. In particular, because destruction can have a creative character.

According to Schumpeter, creative destruction is the process of change and adaptation of existing industries to novelties [Schneider, 2017]. Schumpeter considered creative destruction as a process that incessantly revolutionizes the economic structure from within, incessantly destroying the old one, incessantly creating a new one. Emerging innovations cause destruction of old products and processes [Schumpeter, 1947]. In his view, consumers, with their unmet needs and demand, play an important role in the economic equilibrium. Consumers' wants are a fundamental force in the theory of circular flow in the economy and businessmen take actions using means and methods of production in order to meet consumer needs.

As shown by the previous experience of many companies, digital technology enables the transfer of many of the market mechanisms to an online, real-time auctioning system. Based on this idea, Uber built their business model by creating a digital technology platform. It operates through mediation between customers in need of car transportation and drivers having unused or underused capacity of their personal cars. Digital technology platforms play a very important role in this process. They are the foundation for the development of new business models, 
offering new opportunities to meet identified market needs as well as to create completely new needs and even new markets. The real-time auctioning system is now being expanded to many areas of the economy. An interesting example of using new possibilities created by digital technology platforms and auctioning systems is Haier Group Corp., which is transforming itself into a platform for entrepreneurship and their employees into self-governing entrepreneurs [Michelman, 2017]. Strong market competition forces companies to take actions to increase their efficiency. This goal can be obtained in many ways and one of them is the reduction of fixed costs. Another action leading to the same goal is increasing the flexibility and agility of the company's operation, its connectedness to the market. All this becomes possible thanks to the use of digital technologies and the transformation of a traditional company into a digital one. "In its transformed state, Haier is no longer a traditional manufacturing corporation so much as a platform that provides financing, support, and coordination for microenterprises all focused on developing products and services for the "smart home", the internet of things (IoT)-based concept of a fully connected and networked household" [Michelman, 2017]. For this purpose, the company has implemented a new management model called Rendanheyi, thanks to which the company is closer to the end user of its products. As a result, they can increasingly engage consumers in co-creating new innovative products and services. The Haier digital platform does not only enable better use of internal resources but also, thanks to the platform's availability to external entrepreneurs interested in cooperation, it enables the use of external resources and human potential from all over the world. In this way, the company is transforming into a network organization. There are more and more companies which make the transition from a structural to a network organization thanks to digital technology. Digital transformation, which is driving this transition, creates powerful new capabilities for company development and market competition. Digital transformation based on artificial intelligence, robotics, cognitive computing, Big Data and the Internet of Things helps companies to optimize their business in order to meet consumer demands and experience. Digital companies can serve many customers immediately and at very little cost. They can compete in new ways thanks to the use of converging digital technologies and new data sources. Due to the simultaneous implementation of a bundle of digital technologies, many traditional businesses are being "crushed" by the digital companies such as Uber, Netflix or Amazon.

An important issue for any contemporary company is its innovation. As shown by Schumpeter in his work, an entrepreneur, thanks to his skills and involvement in using the production factors: land, labor and capital, creates new entities, new products and services, and even markets. Thanks to his creativity, innovations arise and he is an innovator who contributes significantly to the economic development. For Schumpeter, an entrepreneur is an innovator. One can draw a conclusion about the bottom-up nature of innovation, closely related to entrepreneurship. The history of business development goes through stages - starting from a small company, through a medium one to a large, global corporation. Analyzing the essence of innovation, it can be demonstrated that in the way of company growth the idea of 
innovation begins to break away from entrepreneurship. In a small and mediumsized company, the entrepreneur is the driver of its innovation. However, the growth of the company usually results in the innovative activity beginning to separate from the business activity - innovation is handled by engineers employed for this purpose, who do not need to have, and often do not have the features of an entrepreneur.

TABLE 1

\section{Innovation and entrepreneurship in companies}

\begin{tabular}{|l|l|}
\hline \multicolumn{1}{|c|}{$\begin{array}{c}\text { The period } \\
\text { of development }\end{array}$} & \multicolumn{1}{c|}{ Innovation and entrepreneurship } \\
\hline $\begin{array}{l}\text { Until the end of the } \\
\text { first half of the 20th } \\
\text { century }\end{array}$ & $\begin{array}{l}\text { Entrepreneur as an innovator creating and commercializing inno- } \\
\text { vations. Close links of innovation and entrepreneurship. Schum- } \\
\text { peter's view - an innovator entrepreneur who effectively uses } \\
\text { production factors, providing innovation to the market, drives } \\
\text { economic growth. }\end{array}$ \\
\hline $\begin{array}{l}\text { Second half of the } \\
\text { 20th century }\end{array}$ & $\begin{array}{l}\text { The following separation of innovation from entrepreneurship. } \\
\text { The innovations are dealt with by specialized company employees } \\
\text { (engineers) developing highly advanced technologies. The } \\
\text { innovator ceases to be an entrepreneur. }\end{array}$ \\
\hline $\begin{array}{l}\text { The beginning of } \\
\text { the 21st century }\end{array}$ & $\begin{array}{l}\text { Transformation of companies based on digital technologies. The } \\
\text { use of digital platforms allowing the transfer of some managerial } \\
\text { competences to employees, forcing them to be more independent } \\
\text { and expecting entrepreneurial attitudes. Back to the idea of } \\
\text { Schumpeter in a new version - an enterprising employee-inno- } \\
\text { vator. Factors of production owned by the company, which } \\
\text { becomes a network of employees, teams and individuals } \\
\text { cooperating on the digital platform as well as consumers who are } \\
\text { co-creators of innovation. }\end{array}$ \\
\hline
\end{tabular}

Source: own elaboration.

\section{Conclusions}

Analyzing the digital transformation of the Haier company, it is possible to formulate the conclusion that digital technologies and, in particular, digital technology platforms offer the possibility of returning to the original idea of the entrepreneur as an innovator. In the new digital model of the company based on the digital platform, each employee becomes an entrepreneur and at the same time has the opportunity to create innovation in close cooperation with the end user, and thus be an entrepreneur and innovator. It follows that the future of enterprises is the ever-increasing digitization which forces the flattening of the hierarchical structure and offering greater independence to the units (teams). Thanks to this, the employees are not only the executors of their managers' orders anymore and, gaining more and more 
independence in making decisions, they must become more and more entrepreneurial. It can therefore be assumed that in the 21 st century a return to Schumpeter's idea of an innovator entrepreneur will be expected, in a new form, in which not only an entrepreneur (company owner) is an innovator, but also every employee of a large corporation is an entrepreneur and innovator. Moreover, thanks to digital technologies, this enterprising employee-innovator will be very close to the consumer who will become a co-creator of innovation.

Digital transformation of enterprises is the novel use of digital technologies in order to implement traditional business processes and create new ones. It should be remembered that digital transformation is not only the transfer of all processes to the digital format, but, above all, a significant change in thinking about the company's functioning, its processes, products (services), partners and consumers. This requires a new look at the entire company, its business environment and its business model. Taking this into account, it can be assumed that many elements of digital transformation are in the nature of innovation. On the other hand, the digital transformation of a company can influence it in a positive way and be the source of its innovativeness.

\section{References}

Agarwal A., 2018, From product to platform: The secret to building $A \$ 10$ billion SaaS business, https://www.forbes.com/sites/valleyvoices/2018/08/14/secrets-to-10-billionsaas/\#1ce9e5e77df6 [date of entry: 12.12.2018].

Berman S.J., 2012, Digital transformation: opportunities to create new business models, "Strategy \& Leadership", vol. 40, pp. 16-24, DOI: 10.1108/10878571211209314.

Christensen C.M., 1997, The innovator's dilemma: when new technologies cause great firms to fail, Harvard Business School Press, Boston, Massachusetts.

de Reuver M., Basole R.C., Sorensen C., 2018, The digital platform: a research agenda, "Journal of Information Technology", vol. 33(2), pp. 124-135, DOI: 10.1057/ s41265-016-0033-3.

Kletzkine J., 2018, Digital transformation doesn't mean innovation, https://www.forbes. $\mathrm{com} /$ sites/startupnationcentral/2018/05/31/digital-transformation-doesntmean-innovation/\#ad710487c0f5 [date of entry: 28.02.2019].

Michelman P., 2017, Leading to become obsolete, "MIT Sloan Management Review", vol. 59(1).

Parker G.G., van Alstyne M.W., Choudary S.P., 2016, Platform Revolution: How Networked Markets are Transforming the Economy and How to Make Them Work for You, Norton \& Co., New York.

Schneider H., 2017, Creative Destruction and the Sharing Economy: Uber as Disruptive Innovation, Edward Elgar Publishing, pp. 63-91.

Schumpeter J.A., 1912, The Theory of Economic Development, tenth printing 2004, Transaction Publishers, New Brunswick, New Jersey. 
Schumpeter J.A., 1934, The theory of economic development. An Inquiry into Profits, Capital, Credit, Interest, and the Business Cycle, Transaction Publishers, New Brunswick and London.

Schumpeter J.A., 1947, Capitalism, Socialism and Democracy, 2nd ed., Harper \& Brothers, New York.

Westerman G., Bonnet D., McAfee A., 2014, Leading digital. Turning technology into business transformation, Harvard Business Review Press, Boston, Massachusetts. 